[Chem. Pharm. Bull.

$[35$ (1) $413-415$ (1987) $]$

\title{
3,4-Secolupane-Type Triterpene Glycosyl Esters from Leaves of Acanthopanax divaricatus SEEM
}

\author{
Kazuhiro Matsumoto, Ryoji Kasai, Fujiko Kanamaru, \\ Hiroshi KoHda and Osamu TaNaKa* \\ Institute of Pharmaceutical Sciences, Hiroshima University School of Medicine, \\ Kasumi, Minami-ku, Hiroshima 734, Japan
}

(Received July 4, 1986)

\begin{abstract}
From leaves of Acanthopanax divaricatus (Araliaceae), two 3,4-secolupane type triterpene glycosyl esters, chiisanoside and isochiisanoside, were isolated, both of which have already been isolated from leaves and stem-bark of $A$. chiisanensis. Besides these compounds, a new glycoside named divaroside and hyperin(quercetin-3-O- $\beta$-D-galactopyranoside) were also isolated from the leaves. Divaroside was established to be the $\beta$-D-glucopyranosyl $(1 \rightarrow 6)-\beta$-D-glucopyranosyl ester of chiisanogenin.
\end{abstract}

Keywords_-Acanthopanax divaricatus; Araliaceae; divaroside; chiisanoside; isochiisanoside; hyperin; 3,4-secolupane-type triterpene; oligo-glycosyl ester

Recently, we reported the isolation and structural determination of three novel 3,4secolupane-type triterpene glycosyl esters, chiisanoside (1) and its two homologues, isochiisanoside (2) and the methyl ester of 2(3), from the leaves and stem-bark of Acanthopanax chiisanensis NAKAI (Araliaceae), ${ }^{1,2)}$ which is a Korean folk medicine used as a tonic, an anti-rheumatic and an anti-inflammatory. This is the first example of the isolation of 3,4-seco-triterpene glycosides from a natural source.

As a continuation of our work on glycoside constituents of Acanthopanax species, the chemical constituents of leaves of $A$. divaricatus SEEM (Japanese plant name: Keyama-ukogi), which grows widely in Japan, have been studied.

A methanolic extract of the leaves of Acanthopanax divaricatus (collected in Hiroshima) was defatted with ether and repeatedly chromatographed to give a new glycoside named divaroside (4) (yield: $0.03 \%$ ) together with the known glycosides, chiisanoside (1) (yield: $3.0 \%$ ), isochiisanoside (2) (yield: $0.09 \%$ ) and hyperin (quercetin-3- $O-\beta$-D-galactopyranoside) (5) $(0.37 \%)$. The known glycosides 1 and 2 were identified by comparison of their proton and carbon-13 nuclear magnetic resonance $\left({ }^{1} \mathrm{H}\right.$ - and $\left.{ }^{13} \mathrm{C}-\mathrm{NMR}\right)$ spectra, electron impact mass spectra (EI-MS) of the trimethylsilyl ether and optical rotation $\left([\alpha]_{\mathrm{D}}\right)$ with those of authentic samples, and the identification of $\mathbf{5}$ was established by comparison of the melting point ( $\mathrm{mp}$ ) and ${ }^{13} \mathrm{C}-\mathrm{NMR}$ spectrum with reference data. ${ }^{3,4)}$

Acid hydrolysis of $\mathbf{4}$ gave D-glucose. ${ }^{5)}$ The ${ }^{13} \mathrm{C}-\mathrm{NMR}$ signals due to the aglycone moiety of 4 (Table I) were observed at almost the same positions as those of $\mathbf{1}$, indicating that $\mathbf{4}$ is a glycosyl ester of chiisanogenin (6). ${ }^{2)}$ The ${ }^{1} \mathrm{H}$ - and ${ }^{13} \mathrm{C}$-NMR spectra showed the presence of two glucosyl units. The EI-MS of the trimethylsilyl ether of 4 exhibited fragment ions at $\mathrm{m} / \mathrm{z}$ $829\left[(\mathrm{Glc}-\mathrm{Glc}) \mathrm{TMS}_{7}\right], 451\left[(\mathrm{Glc}) \mathrm{TMS}_{4}\right]$ and $583\left[\mathrm{Glc}(\mathrm{TMS})_{4}-\mathrm{OCH}_{2}-\mathrm{CH}=\mathrm{O}^{+}-\mathrm{TMS}\right.$, a characteristic fragment ion due to aldohexosyl $(1 \rightarrow 6)$ aldohexose]. ${ }^{6)}$ Inspection of the ${ }^{13} \mathrm{C}$-NMR signals due to the sugar moiety revealed the presence of a $\beta$-gentiobiosyl ester moiety in 4 (Table I). Based on these results, 4 is formulated as the $\beta$-D-glucopyranosyl $(1 \rightarrow 6)-\beta$-Dglucopyranoside of (1R)-1,11 $\alpha$-dihydroxy-3,4-seco-lupa-4(23),20(29)-diene-3,28-dioic acid 


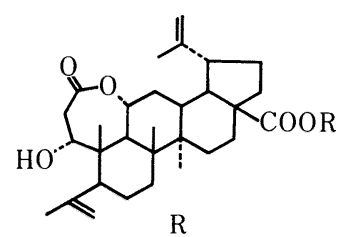

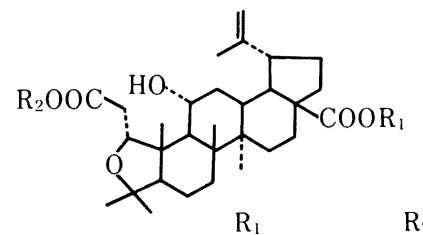

$1:-\beta-\mathrm{Glc}^{-}-\beta-\mathrm{Glc}^{4}-\alpha-\mathrm{Rha}$

$2:-\beta-\mathrm{Glc}^{6}-\beta-\mathrm{Glc}^{4}-\alpha-\mathrm{Rha} \quad \mathrm{H}$

$4:-\beta-\mathrm{Glc}^{-6} \beta-\mathrm{Glc}$

$3:-\beta-\mathrm{Glc}^{6}-\beta-\mathrm{Glc}^{4}-\alpha-\mathrm{Rha} \quad \mathrm{CH}_{3}$

$6: \mathrm{H}$<smiles></smiles>

Chart 1

Table I. ${ }^{13} \mathrm{C}$ Chemical Shifts $(\delta)$ in $\mathrm{C}_{5} \mathrm{D}_{5} \mathrm{~N}$

\begin{tabular}{|c|c|c|c|c|c|c|c|}
\hline & & 1 & 4 & & & 1 & 4 \\
\hline Aglycone & 1 & 75.0 & 75.1 & Sugar & Glc-1 & 95.2 & 95.4 \\
\hline \multirow{29}{*}{ moiety } & 2 & 38.6 & 38.8 & moiety & -2 & 73.8 & 74.1 \\
\hline & 3 & 173.1 & 173.0 & & -3 & 78.4 & $78.1^{b)}$ \\
\hline & 4 & 147.6 & 147.7 & & -4 & 70.5 & 70.9 \\
\hline & 5 & 49.5 & 49.6 & & -5 & 76.3 & $78.4^{b)}$ \\
\hline & 6 & 25.1 & 25.1 & & -6 & 69.2 & 69.5 \\
\hline & 7 & 33.4 & 33.5 & & Glc-1' & 104.7 & 105.3 \\
\hline & 8 & 41.6 & 41.7 & & $-2^{\prime}$ & 75.2 & 75.2 \\
\hline & 9 & 44.0 & 44.1 & & $-3^{\prime}$ & 76.9 & $78.4^{b)}$ \\
\hline & 10 & 44.0 & 44.1 & & $-4^{\prime}$ & 78.4 & 71.5 \\
\hline & 11 & 70.2 & 70.5 & & $-5^{\prime}$ & 77.8 & 78.7 \\
\hline & 12 & 32.2 & 32.2 & & $-6^{\prime}$ & 61.3 & 62.6 \\
\hline & 13 & 35.2 & 35.2 & & Rha-1 & 102.5 & \\
\hline & 14 & 42.1 & 42.2 & & -2 & $72.5^{b)}$ & \\
\hline & 15 & 30.7 & 30.8 & & -3 & $72.3^{b)}$ & \\
\hline & 16 & 32.5 & 32.2 & & -4 & 73.8 & \\
\hline & 17 & 56.7 & 56.8 & & -5 & 70.2 & \\
\hline & 18 & 47.5 & 47.6 & & -6 & 18.3 & \\
\hline & 19 & 49.5 & 49.6 & & & & \\
\hline & 20 & 150.7 & 150.1 & & & & \\
\hline & 21 & 29.5 & 29.5 & & & & \\
\hline & 22 & 36.8 & 36.8 & & & & \\
\hline & 23 & 113.9 & 113.9 & & & & \\
\hline & 24 & 23.5 & 23.5 & & & & \\
\hline & 25 & $18.9^{a)}$ & $18.9^{a)}$ & & & & \\
\hline & 26 & $17.9^{a)}$ & $18.0^{a)}$ & & & & \\
\hline & 27 & 13.8 & 13.8 & & & & \\
\hline & 28 & 175.0 & 175.1 & & & & \\
\hline & 29 & $18.9^{a)}$ & $19.1^{a)}$ & & & & \\
\hline & 30 & 110.6 & 110.7 & & & & \\
\hline
\end{tabular}

$a, b)$ These assignments may be interchanged in each column. Glc, $\beta$-D-glucopyranosyl; Rha, $\alpha$-Lrhamnopyranosyl.

3,11-lactone (=desrhamno-chiisanoside) (Chart 1).

The preliminary investigation of methanolic extracts of leaves of five other Japanese Acanthopanax spp. (A. hypoleucus MAKINO, A. japonicus Fr. et SAV., A. sciadophylloides Fr. 
et SAV., A. senticosus HARMS and A. spinosus MIGUEL) by thin layer chromatography (TLC) indicated the absence of these 3,4-secolupane type triterpene glycosides, suggesting a unique taxonomical position of $A$. divaricatus and $A$. chiisanensis in this genus.

\section{Experimental}

General Procedure - Melting points were determined on a Yanaco micro hot stage and are uncorrected. Optical rotations were measured with a Union PM-101 automatic digital polarimeter. Infrared (IR) spectra were taken on a Shimadzu IR-408 spectrometer. NMR spectra were recorded on a JEOL FX-100 instrument using tetramethylsilane (TMS) as an internal standard. For gas liquid chromatography (GLC), a Shimadzu GC-6A apparatus was used. MS were taken on a JEOL JMS-01-SG-2 spectrometer by the direct inlet method; ionization voltage $75 \mathrm{eV}$. For column chromatography, Kieselgel 60 (70-230 mesh, Merck), LiChroprep RP-8 (40-63 $\mu \mathrm{m}$, Merck), Diaion HP-20 (Mitsubishi Chem. Ind. Co., Ltd.) and Sephadex LH-20 (Pharmacia) were used. All solvent systems for chromatography were homogeneous.

Extraction and Separation of Glycosides - Dried leaves of Acanthopanax divaricatus (148 g) collected in Hiroshima prefecture were extracted with $\mathrm{MeOH}$, and the $\mathrm{MeOH}$ extract was concentrated to dryness. The residue (37.8g) was suspended in $\mathrm{H}_{2} \mathrm{O}$ and then washed with $\mathrm{Et}_{2} \mathrm{O}$. The aqueous layer was chromatographed on a column of highly porous polymer (Diaion HP-20) and eluted with $\mathrm{H}_{2} \mathrm{O}, 60 \% \mathrm{MeOH}, 80 \% \mathrm{MeOH}, \mathrm{MeOH}$ and $\mathrm{Me}_{2} \mathrm{CO}$, successively. The $60 \% \mathrm{MeOH}$ eluate was chromatographed on a reversed-phase column (LiChroprep RP-8, 65\% $\mathrm{MeOH})$ to give crude $\mathbf{5}$ and $\mathbf{2}$. The crude $\mathbf{5}$ and $\mathbf{2}$ were purified by column chromatography on Sephadex LH-20 $(\mathrm{MeOH})$ and silica gel $\left(\mathrm{CHCl}_{3}-\mathrm{MeOH}-\mathrm{H}_{2} \mathrm{O}(6: 4: 1)\right)$ to give 5 (78 mg) and 2 (a white powder, $19 \mathrm{mg}$ ), respectively. The $80 \% \mathrm{MeOH}$ eluate was subjected to chromatography on a LiChroprep RP- 8 column $(68 \% \mathrm{MeOH})$ and then a silica gel column $\left(\mathrm{CHCl}_{3}-\mathrm{MeOH}-\mathrm{H}_{2} \mathrm{O}\right)(10: 5: 1)$ to give two fractions (fr. 1 and fr. 2). Fraction 1 was purified by high performance liquid chromatography (column, TSK-GEL ODS-120T $21 \mathrm{~mm} \times 30 \mathrm{~cm}$; solvent, $60 \% \mathrm{MeOH}$; flow rate, $7 \mathrm{ml} / \mathrm{min}$; detection, RI) to give $\mathbf{4}(16 \mathrm{mg})$. Fraction 2 was chromatographed on LiChroprep RP-8 to give $\mathbf{1}(1.4 \mathrm{~g})$.

The identification of 1 and 2 was established by direct comparison (TLC, $[\alpha]_{\mathrm{D}},{ }^{1} \mathrm{H}$ - and ${ }^{13} \mathrm{C}-\mathrm{NMR}$ ) with authentic samples. The identification of 5 was established by comparison of the melting point and ${ }^{13} \mathrm{C}$-NMR data with reference data. ${ }^{3,4)}$

Compound 4: a white powder, $[\alpha]_{\mathrm{D}}^{19}+30.0^{\circ}(c=0.59, \mathrm{MeOH})$. Anal. Calcd for $\mathrm{C}_{42} \mathrm{H}_{64} \mathrm{O}_{15} \cdot 4 \mathrm{H}_{2} \mathrm{O}: \mathrm{C}, 57.26 ; \mathrm{H}$, 8.24. Found: C, 57.11; H, 8.24. IR (Nujol) $\mathrm{cm}^{-1}: 3450(\mathrm{OH}), 1750,1710(\mathrm{COOR}), 1640,890\left(\mathrm{C}=\mathrm{CH}_{2}\right) .{ }^{1} \mathrm{H}-\mathrm{NMR}$ $\left(\mathrm{C}_{5} \mathrm{D}_{5} \mathrm{~N}, 100 \mathrm{MHz}\right) \delta: 6.22\left(1 \mathrm{H}, \mathrm{d}, J=8 \mathrm{~Hz}\right.$, anomeric $\mathrm{H}$ of $\left.\mathrm{Glc}^{\prime}\right), 5.01(1 \mathrm{H}, \mathrm{d}, J=8 \mathrm{~Hz}$, anomeric $\mathrm{H}$ of $\mathrm{Glc})$. ${ }^{13} \mathrm{C}$-NMR data are given in Table I.

Acid Hydrolysis of 4 and Identification of the Resulting Monosaccharide ${ }^{5}$ - $-A$ sample $(10 \mathrm{mg})$ was heated with $3.5 \% \mathrm{HCl}$ in $\mathrm{H}_{2} \mathrm{O}$-dioxane $(1: 1,1 \mathrm{ml})$ in a sealed micro-tube at $80 \mathrm{C}$ for $3 \mathrm{~h}$. The reaction mixture was diluted with $\mathrm{H}_{2} \mathrm{O}$ and then washed with $\mathrm{CHCl}_{3}$. The aqueous layer was neutralized with Amberlite MB-3 ion exchange resin and then concentrated to give a sugar fraction. A solution of the sugar fraction $(1 \mathrm{mg})$ in $50 \mu \mathrm{l}$ of $\mathrm{H}_{2} \mathrm{O}$ was treated with a solution of $\mathrm{L}-(-)-\alpha$-methylbenzylamine $(9 \mathrm{mg})$ and $\mathrm{NaBH}_{3} \mathrm{CN}(0.6 \mathrm{mg})$ in $50 \mu \mathrm{l}$ of EtOH, and the mixture was kept at $40 \mathrm{C}$ for $4 \mathrm{~h}$. Then several drops of acetic acid were added, and the whole was concentrated to dryness. The residue was trimethylsilylated with $N$-trimethylsilylimidazole and subjected to GLC analysis (dual flame ionization detector; carrier gas, He $2.5 \mathrm{ml} / \mathrm{min}$; WCOT glass capillary column $(0.25 \mathrm{~mm}$ i.d. $\times 25 \mathrm{~m})$ coated with Carbowax $20 \mathrm{M}$; isothermal, $150^{\circ} \mathrm{C}$; injection temperature, $190^{\circ} \mathrm{C}$; retention time, $46.29 \mathrm{~min}$ ). D-Glucose was identified by comparison of the retention time with that of an authentic sample.

\section{References}

1) D.-R. Hahn, R. Kasai, J.-H. Kim, S. Taniyasu and O. Tanaka, Chem. Pharm. Bull., 32, 1244 (1984).

2) R. Kasai, K. Matsumoto, S. Taniyasu, O. Tanaka, J.-H. Kim and D.-R. Hahn, Chem. Pharm. Bull., 34, 3284 (1986).

3) S. Matsuura and M. Iinuma, Yakugaku Zasshi, 97, 452 (1977).

4) K. R. Markham, B. Ternai, R. Stanley, H. Geiger and T. J. Mabry, Tetrahedron, 34, 1389 (1978).

5) R. Oshima, J. Kumanotani and C. Watanabe, J. Chromatogr., 259, 159 (1983).

6) N. K. Kochetkov, O. S. Chizhov and N. V. Molodtov, Tetrahedron, 24, 5587 (1968). 